\title{
TOTAL BLADDER REPLACEMENT WITH DE-EPITHELIALIZED ILEUM. EXPERIMENTAL STUDY IN DOGS
}

\author{
FÁBIO O. VILAR, LUIZ A. P. DE ARAÚJO, SALVADOR V.C. LIMA \\ Nucleus of Experimental Surgery, Department of Surgery, Federal University of Pernambuco, Recife, PE, \\ Brazil
}

\begin{abstract}
Objective: To assess the value of the silicone modeler in preventing graft retraction in dogs undergoing bladder replacement with de-epithelialized ileum.

Materials and Methods: Twelve female dogs underwent total cystectomy and bladder replacement by neobladder made of demucosalized ileal segment, comparing the group with modeler (group I) and the group without modeler (group II). Cystometry data, graft epithelization and radiological assessment (cystography and excretory urography) were analyzed.

Results: Neobladder capacity, at 2 months, ranged from 50 to $250 \mathrm{~mL}$ (mean $191 \mathrm{~mL}$ ) and from 5 to $60 \mathrm{~mL}$ (mean $22 \mathrm{~mL}$ ) and at 6 months, from 60 to $270 \mathrm{~mL}$ (mean $202.5 \mathrm{~mL}$ ) and from 5 to $75 \mathrm{~mL}$ (mean- $30.5 \mathrm{~mL}$ ), respectively in groups I and II, with a statistically significant difference between groups. After 30 days, postoperatively the presence of transitional epithelium was observed in all fragments obtained by biopsy.

Conclusion: The use of the intravesical silicone modeler prevented the retraction of the neobladder of de-epithelialized ileum.
\end{abstract}

Key words: bladder; ileum; epithelium; prostheses and implants

Int Braz J Urol. 2004; 30: 237-44

\section{INTRODUCTION}

Efforts to augment or replace the bladder are old $(1,2)$, and most commonly digestive tract segments were used for this purpose (3). Considering, however, the characteristics of intestinal mucosa, structurally and functionally distinct from the bladder, problems such as production of secretions, infection, electrolytic changes and even developing of tumors still await for a definitive solution (4). Thus, in order to overcome such difficulties, some authors suggested using de-epithelialized flaps of digestive tract (5-7). Martin used a Foley stent balloon aiming to distend the de-epithelialized graft (7). Other authors have tried to reproduce experiments with de-epithelialized segments of the digestive system (8-10).
Given the mucosecreting and absorbing nature of the digestive epithelium, problems resulting from mucous secretion and metabolic changes are, sometimes, difficult to solve (11). Intestinal neobladder could be made with digestive tract segments lacking their original mucosa (de-epithelialized) over which a layer of transitional epithelium would develop, whether from the original bladder or from grafted islets of transitional epithelium (5-7). Our studies with de-epithelialized colon have allowed for improving bladder capacity through the use of a silicone modeler placed inside the neobladder and submitted to a slight distension. This distension allows the de-epithelialized flap not to retract, and thus it can undergo the epithelization process from the existing bladder (12). 
The present study applies the de-epithelialized ileal segment for bladder replacement and analyzes the role of the silicone modeler in preventing graft retraction and in its epithelization.

\section{MATERIALS AND METHODS}

Animals underwent total cystectomy and bladder replacement by neobladder of demucosalized ileal segment, comparing the group with modeler (group I) and the group without modeler (group II). Graft epithelization, cystometry data and radiological assessment (cystography and excretory urography) were analyzed.

The research project was approved by the Committee for Research Ethics from the Health Science Center of Federal University of Pernambuco.

Twelve cross-bred female dogs, apparently healthy, weighting between 13 and $27 \mathrm{~kg}$ (mean 16 $\mathrm{kg} /$ median $16.5 \mathrm{~kg}$ ) were operated, among which 10 survived for longer than 60 days and were used for this study.

All animals were operated and maintained at the Nucleus of Experimental Surgery of Federal University of Pernambuco. On the first postoperative day they were fed with a liquid meal, which was advanced to solid meals according to each animal's acceptance. All animals were maintained on therapeutic antibiotic treatment with gentamicin $(80 \mathrm{mg} /$ day $)$ for 10 days following each manipulation, and from then on, prophylactic therapy with nitrofurantoin $(100 \mathrm{mg} /$ day $)$ until death.

\section{Surgical Technique}

Animals were weighted and underwent puncturing of the radial vein in one of the front paws, with 19 or 21 butterfly-type needle. They underwent intravenous anesthesia with ketamine $(1 \mathrm{mg} / \mathrm{kg})$, fentanyl citrate $(1 \mathrm{mg} / \mathrm{kg})$ and pentobarbital sodium $(25$ $\mathrm{mg} / \mathrm{kg}$ ). After being positioned in dorsal decubitus, the animals were intubated with an orotracheal tube and maintained under controlled ventilation, using the muscle relaxant pancuronium bromide $(1 \mathrm{mg} / \mathrm{kg})$. All animals received between 30 and $50 \mathrm{~mL} / \mathrm{kg} / \mathrm{h}$ of $0.9 \%$ physiological saline solution or Ringer lactate, during surgery.
The access approach was median laparotomy measuring approximately $20 \mathrm{~cm}$, until the pubic symphysis. Following the inspection of every abdominal organ, a $45-\mathrm{cm}$ ileal segment with suitable vascular pedicle was isolated (Figure-1 A), and intestinal transit was reconstituted by termino-terminal ileum-ileal anastomosis, with continuous sutures in 2 planes, using 3-0 chromic catgut suture for the mucosa and 4-0 prolene for seromuscular layer.

The isolated ileal segment had its seromuscular layer separated from the mucosa, as following. Inserting a 14 or $16 \mathrm{~F}$ Foley catheter within the lumen and insufflating the balloon with $10 \mathrm{~mL}$ of distilled water. Blunt dissection with Kelly forceps, and separation of seromuscular layer from the mucosa, on the segment ileal supported by the stent balloon, and longitudinal section on the anti-mesenteric aspect of the seromuscular layer. In order to start the dissection, close to one of the extremities of the isolated ileal segment, with the stent balloon inflated, a circular incision of the seromuscular layer was performed around the entire ileum circumference (Figure-1 B) with 15-blade scalpel. Using the Kelly forceps, the seromuscular layer was separated from the mucosa, with the procedure being complete when the other extremity was reached (Figure-2). Electrocautery was used for hemostasia. Simultaneously, the de-epithelialized area was irrigated with distilled water at a temperature of $5^{\circ} \mathrm{C}$, through a 20 -mL syringe with insulin needle, in order to promote vasoconstriction.

Upon completing the dissection, the mucosa layer was discarded, the ileal segment of the seromuscular layer was configured into an U-shape, and the edges were closed by continuous stitches with 40 chromic catgut suture, so that it nearly formed a demucosalized bowel plate (Figure-3).

Bladder was sectioned at the level of the bladder neck. Ureteral distal ends were dissected and sectioned at the level of their insertion in the bladder. In the region more proximal to the urethral orifice, an orifice measuring approximately $1.5 \mathrm{~cm}$ in diameter was confectioned by suturing the edges of the de-epithelialized ileum, and the anastomosis with the urethra was performed. Suture consisted in separate stitches in 4-0 chromic catgut. 


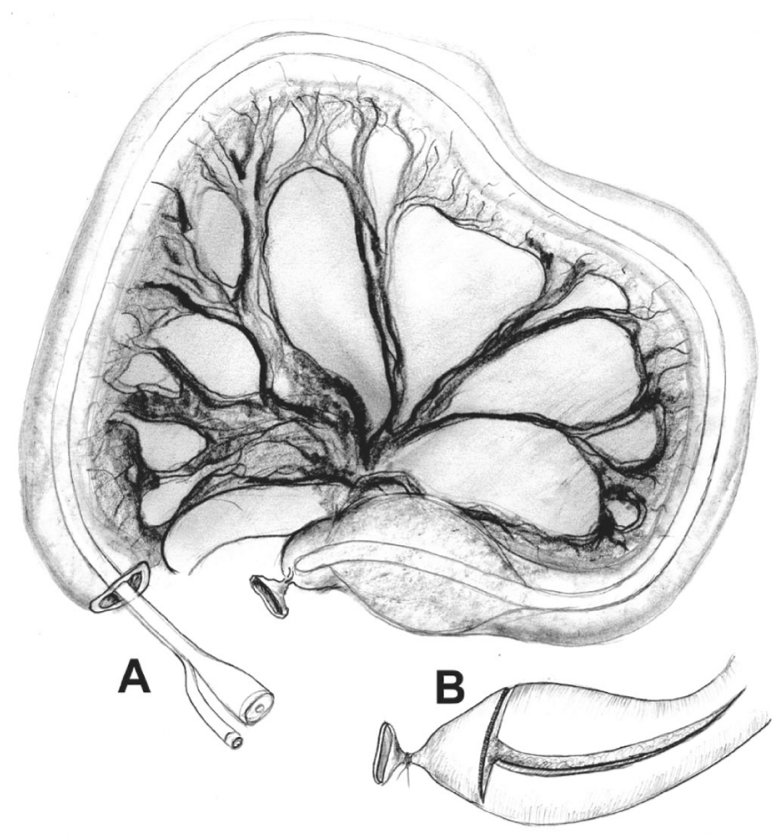

Figure 1 - A) Identification of the ileal segment to be used. $B)$ Detail of seromuscular incision over Foley catheter balloon.

Ureters were anastomosed in the most cephalic region of the ileal plate, with 5-0 monofilament PDS suture in separate stitches. An orifice measuring approximately $0.5 \mathrm{~cm}$ in diameter was made in the ileal wall, passing $1.5 \mathrm{~cm}$ of ureter that was fixed to the internal aspect (de-epithelialized aspect), keep-

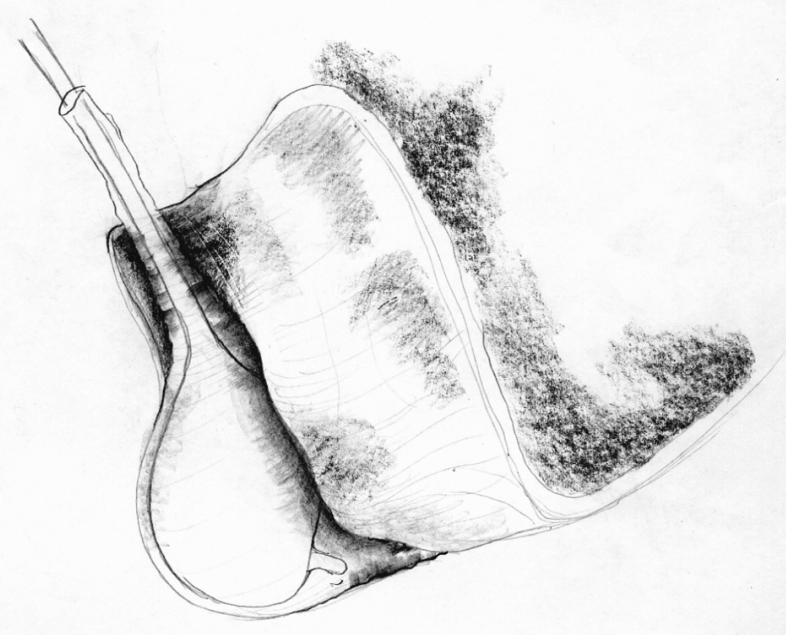

Figure 2 - Final of dissection separating the seromuscular layer from the тисоsa.

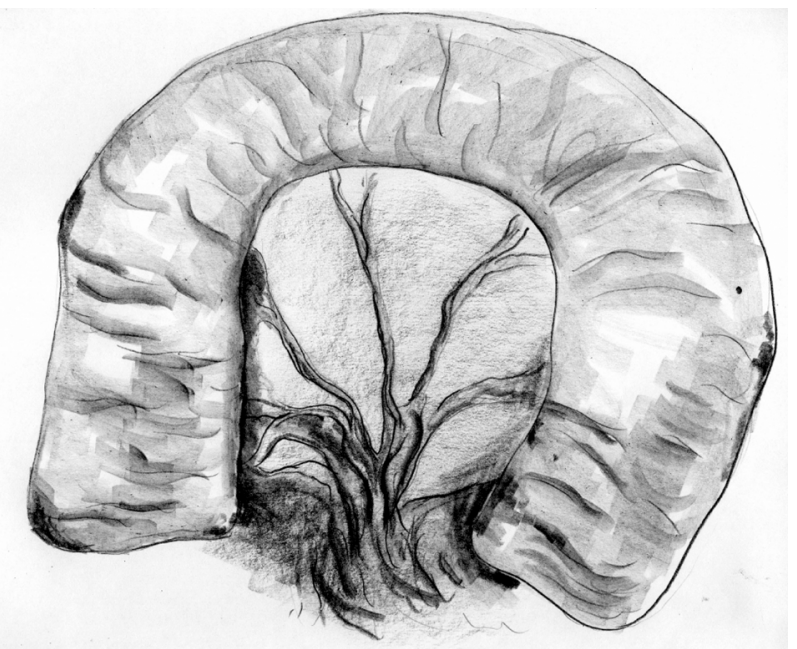

Figure 3 - Ileal segment detubularized and configured to serve as neobladder

ing the catheterization with $4 \mathrm{~F}$ plastic urethral catheter (Figure-4). The extremity of the catheter was left inside the urethra in a silicone tube.

The edge of the ileal plate was fixed with 40 chromic catgut suture in continuous stitches, so that the neobladder was configured into a seemingly spherical shape. After sorting within groups, in the animals from group I, an empty silicone modeler was inserted (Figures-4 and 5).

The silicone modeler was inflated and maintained with $100 \mathrm{~mL}$ of physiological saline solution, after completing the suture and the neobladder confection (Figure-6). The modeler valve was placed in the subcutaneous tissue of the abdominal wall, close to the incision. In the animals from group II, the ileal plate was sutured similarly to group I, though without the modeler.

Closure of the abdominal wall was performed by planes, with separate stitches. The reversion of neuromuscular block was achieved with atropine $(0.01 \mathrm{mg} / \mathrm{kg})$ and neostigmine $(0.03$ to $0.07 \mathrm{mg} / \mathrm{kg})$. The orotracheal tube was removed following the return to spontaneous breathing.

\section{Postoperative period}

For surgical procedures and postoperative assessment examinations, sedation and analgesia were performed with ketamine $(1 \mathrm{mg} / \mathrm{kg})$ and fentanyl citrate $(1 \mathrm{mg} / \mathrm{kg})$ by intravenous approach. 


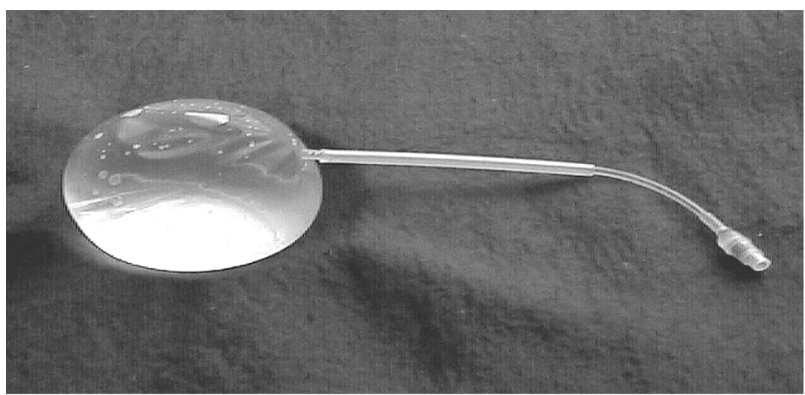

Figure 4 - Vesical silicone modeler.

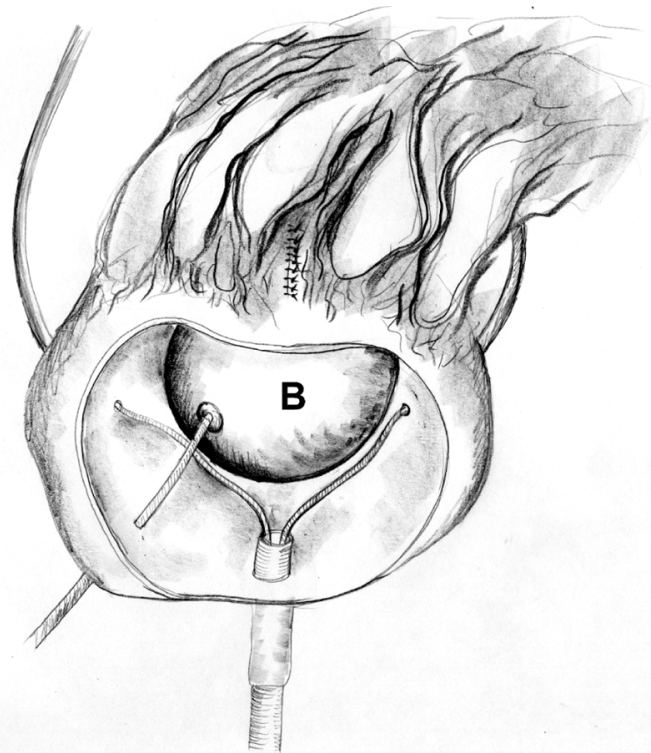

Figure 5 - Reimplantation of ureters. Note catheters in the ureters. The silicone balloon $(B)$ is partially insufflated.

The silicone modeler was removed on the 14th postoperative day through a small abdominal incision measuring approximately $3.0 \mathrm{~cm}$ at the level of the modeler valve, which was in the subcutaneous tissue. After being totally emptied through its valve, the modeler was pulled and removed. The ureteral catheters were also removed at the same occasion by pulling them through the urethra.

The morphologic-functional assessment of the neobladder was performed through radiological study (excretory urography and cystography), cystometry and cystoscopy with biopsy of the graft wall. Cystometry and cystoscopy with biopsy were performed on the same occasion, monthly.

\section{Cystometry}

The cystometry was performed before the biopsy. A $10 \mathrm{~F}$ nelaton catheter was inserted, the neobladder was emptied, and residual urine was measured. Through a second nelaton catheter connected to an external system of the hydration equipment, assembled on a stand with measuring tape, $0.9 \%$ physiological saline solution was infused at an approximate rate of $25 \mathrm{~mL} / \mathrm{min}$. Intravesical tension was measured in $\mathrm{H}_{2} \mathrm{O}$ column $(\mathrm{cm})$, from the point zero, which was settled at the level of the pubic symphysis, with the animal in dorsal decubitus. The container of physiological saline solution was located at $30-\mathrm{cm}$ height from the point zero. All infused volumes and corresponding pressures were measured at every 5 $\mathrm{mL}$ of infusion and put on a graphic. The maximum vesical capacity was considered when fluid extravasation started around the urethral catheter, while infusing the solution. For comparison between groups, the capacity at 2 and 6 postoperative months was considered.

\section{Cystoscopy with Biopsy}

Following the cystometry, a cystoscopy with biopsy was performed, using a $21 \mathrm{~F}$ sheath cystoscope and flexible biopsy forceps. Neobladder biopsies were performed on the lateral wall, fundus and regions close

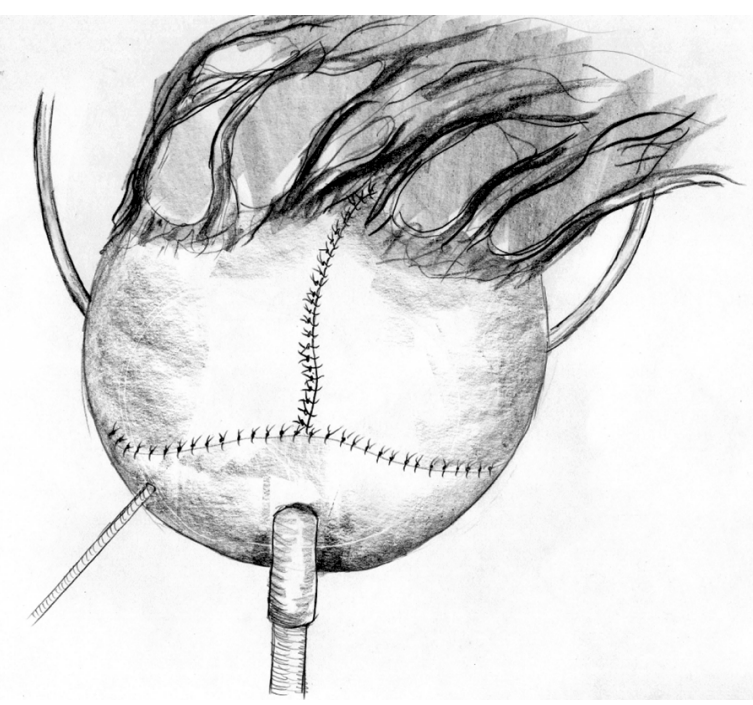

Figure 6 - Final aspect after placement of the balloon that was insufflated with $100 \mathrm{~mL}$ of physiological saline solution. 


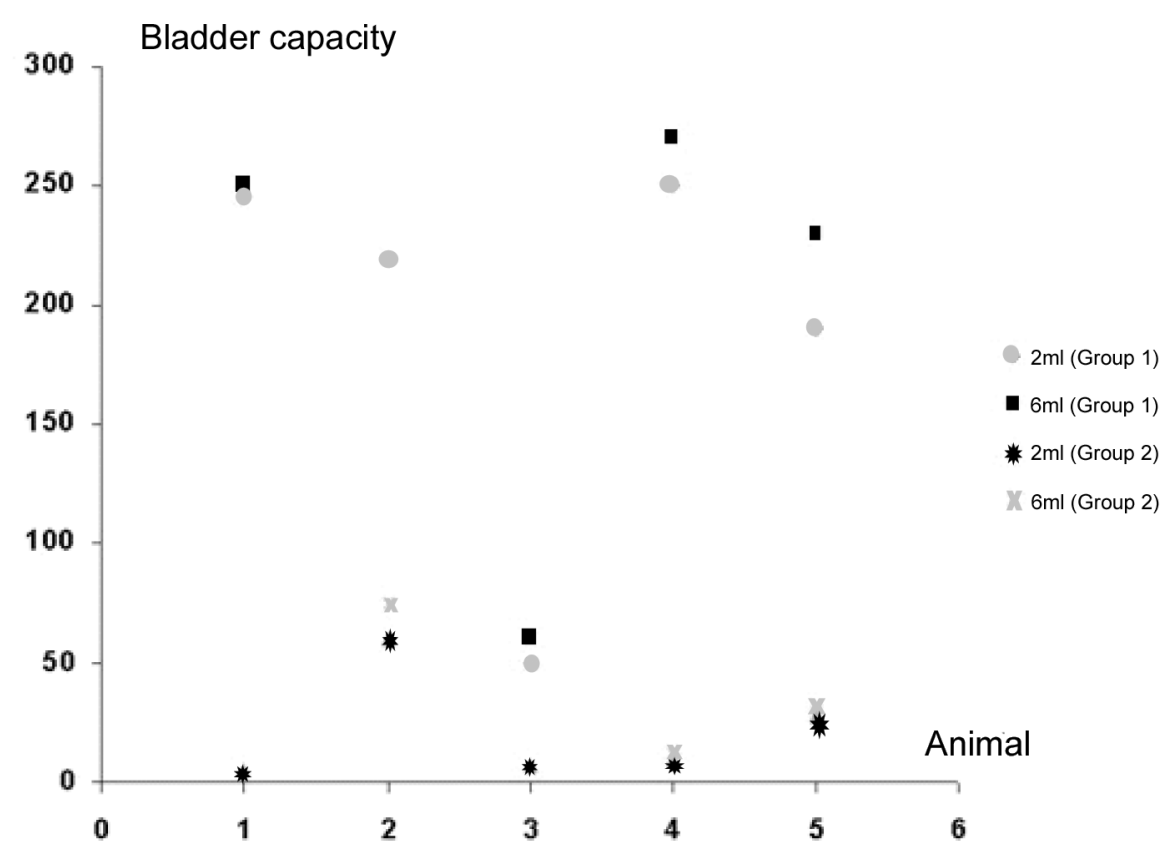

Figure 7 - Bladder capacity of animals from both groups, at 2 months and at 6 months.

to the ureters. Samples were identified, placed in different containers, fixed in $10 \%$ formalin, and processed as usual for histological study. When the animal died, the necropsy was performed with histological analysis of the entire urinary tract.

Cystography and excretory urography were performed 2 or 3 times during the study. In some animals, the urography was not performed.

\section{Statistical Study}

The Student's t-test was used to compare neobladder capacity in animals with and without the use of silicone modeler, with the significance level set at 0.05 or $5 \%$, for assessments at 2 and 6 months.

\section{RESULTS}

Two animals died within the first month following surgery. The main cause was peritonitis due to urine extravasation. Ten animals, 5 in each group, survived for more than 2 months; and eight (4 in each group) survived for more than 6 months. Mean survival in group I was 268.4 days (median 330) and in group II it was 253.6 days (median 240).

Table 1 - Bladder capacity ( $\mathrm{mL}$ ) of animals from groups I and II at 2 and 6 months.

\begin{tabular}{cccccc}
\hline & Group I & & \multicolumn{3}{c}{ Group II } \\
Animals & 2 months & 6 months & Animals & 2 months & 6 months \\
\hline 1 & 245 & 250 & 1 & 5 & - \\
2 & 220 & - & 2 & 60 & 75 \\
3 & 50 & 270 & 3 & 7 & 5 \\
4 & 250 & 230 & 5 & 10 & 12 \\
5 & 190 & & & 28 & 30 \\
\hline
\end{tabular}


Table 2 - " $t$ " test according to bladder capacity $(m L)$ at 2 months.

\begin{tabular}{llc}
\hline Statistics & Group I & Group II \\
\hline Mean & 191 & 22 \\
Variance & 6780 & 534.5 \\
Observations & 5 & 5 \\
Degrees of freedom & 5 & 5 \\
t Statistics & 4.418546 & \\
$\mathrm{P}(\mathrm{T} \leq \mathrm{t})$ one-tail & 0.003451 & \\
T critical one-tail & 3.36493 & \\
\hline
\end{tabular}

\section{Cystometry}

Results for neobladder capacity and statistical study are presented, respectively, in Tables-1, 2 and 3. The evolutional bladder capacity for each animal from groups I and II, at 2 and 6 months, is represented in Figure-7.
Table 3 - " $t$ " test according to bladder capacity $(m L)$ at 6 months.

\begin{tabular}{lll}
\hline Statistics & Group I & Group II \\
\hline Mean & 202.5 & 30.5 \\
Variance & 9291.7 & 991 \\
Observations & 4 & 4 \\
Degrees of freedom & 4 & \\
t Statistics & 3.392388 & \\
$\mathrm{P}(\mathrm{T} \leq \mathrm{t})$ one-tail & 0.013735 & \\
$\mathrm{~T}$ critical one-tail & 2.131846 & \\
\hline
\end{tabular}

\section{Radiological Assessment}

Cystographies showed suitable and ovalshaped neobladders in animals from both groups, with neobladders in group I being visually larger than those in group II (Figures-8 A and B).
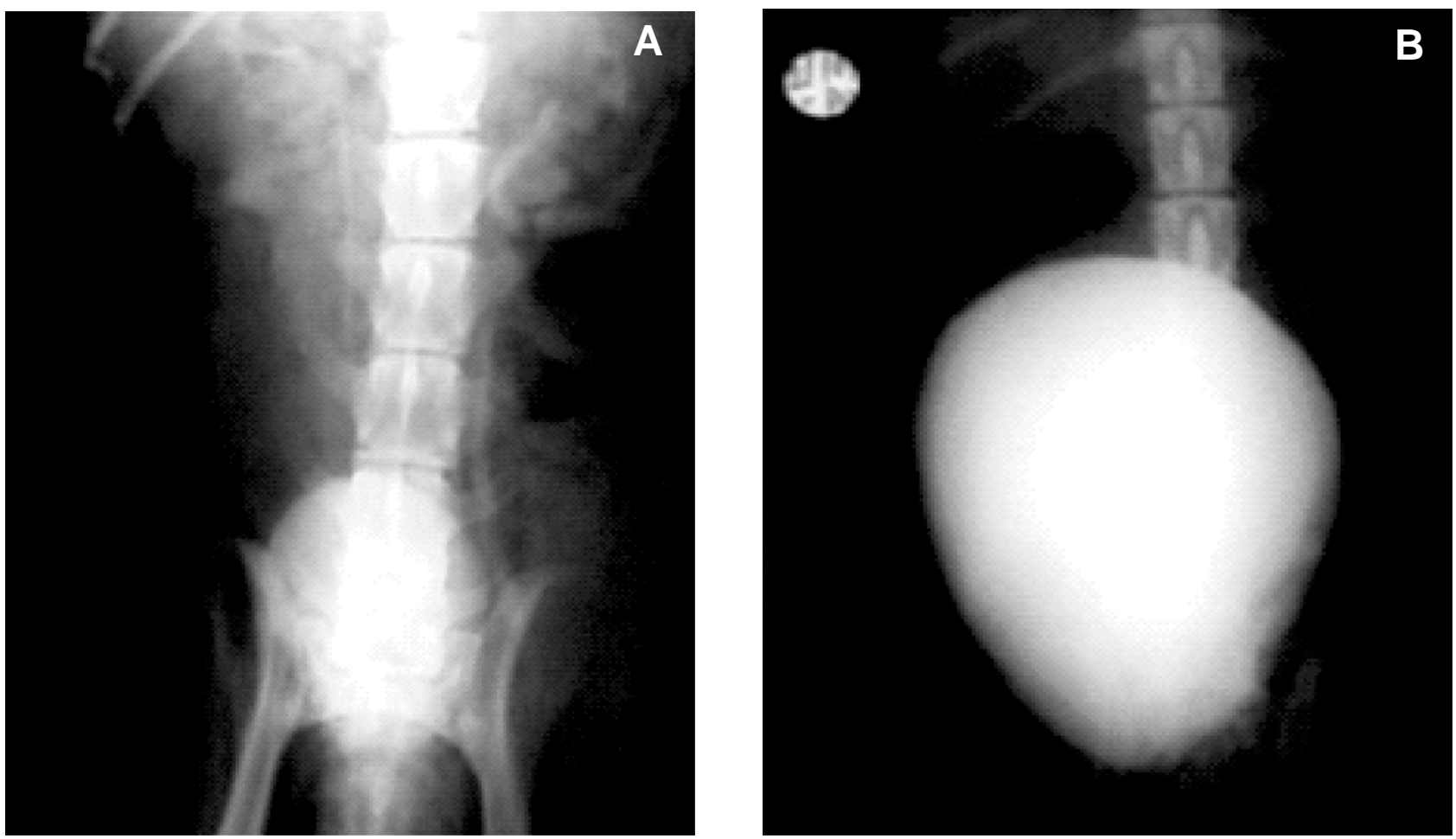

Figure 8 - A) Radiological aspect of bladder in control group. B) Radiological aspect of bladder in the group that used intravesical expander. 


\section{Histological Study}

Transitional epithelium was observed in all fragments obtained by biopsy, both at 30 days postoperatively, and in subsequent ones, in all animals from both groups (Figure-9).

\section{DISCUSSION}

The use of de-epithelialized and balloon-protected intestinal segments had been previously reported in experimental animals. The type of material employed by the researcher (latex Foley stent balloon) was probably improper and limited his studies (7).

Studies for bladder augmentation similar to ours were conducted almost simultaneously by Australian researchers (8). They used de-epithelialized

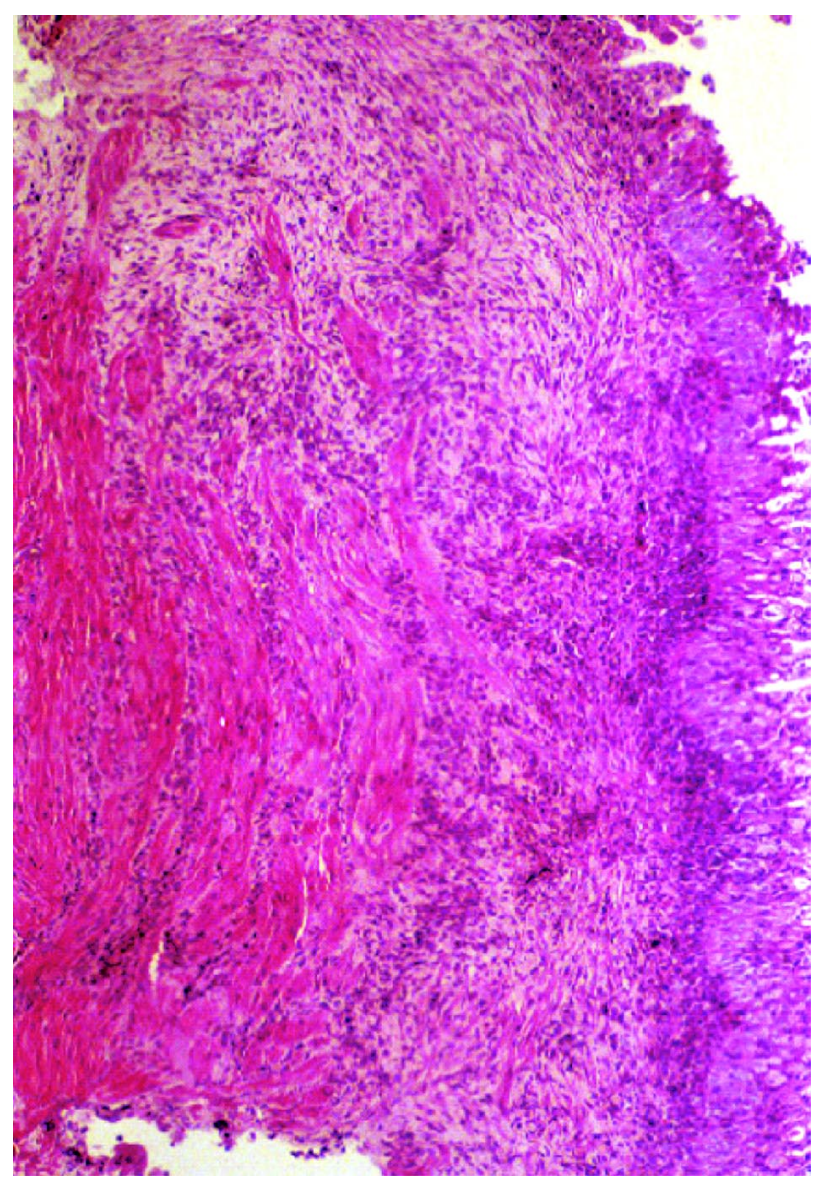

Figure 9 - Histological slide showing growth of stratified epithelium and preservation of musculature $(H E)$. sheep stomach and reported results similar to those obtained in our initial studies with sigmoid colon.

Jednak et al. used a model with sigmoid colon also similar to our initial model, though preserving the submucous layer of the bowel (13). They studied 16 patients, 14 with neurogenic bladder and 2 with sequelae from posterior urethral valve and reported a 2.4 times increase in bladder capacity. Filling pressures decreased by an average of 50\%. Postoperative endoscopic biopsies revealed the presence of colonic epithelium in 3 cases. Four patients required reintervention, with 2 requiring a new augmentation. In an effort to extend the technique of de-epithelialized bowel for use in cases of small bladders or cases of vesical extrophy, some laboratories tried alternative methods for applying these grafts. Merguerian et al. used de-epithelialized grafts of sigmoid colon covered with grafts of cultured transitional epithelium covered by polygalactine (14). Despite the positive results of "in vitro" epithelial seeding, there was no growth when it was applied "in vivo". More recently, Frey et al. used a similar model in mini-pigs. De-epithelialized bowel or stomach were grafted with urothelium islets, removed at the moment of surgery or collected from another animal. Severe contracture of the intestinal graft was observed in all cases (15).

In our study, catheterization of both ureters with the purpose of avoiding contact of urine with the graft seems to have a great importance and facilitates epithelial growth. The idea of maintaining the vesical modeler for 2 weeks is, to a certain extent, casual, since there is only one previous report in this sense, however only one animal was studies (7).

There is a recent study in rats where a silicone "stent" was used inside an augmented bladder obtaining results similar to ours (16).

In relation to the mortality observed in some animals in our study, we attribute it to the fact that dog bladder, as in the majority of animals, is located intraperitoneally and it favored urosepsis, which was triggered by urine extravasation. Similar complications were observed by other researchers in different time periods $(5,16)$.

Despite such mortality, we could study in detail the surviving animals through monthly bladder biopsies and, considering that we had animals that 
survived up to 12 months, the opportunity of performing multiple biopsies in different occasions on the same animal, makes the apparently low number of animals in each group to be projected as a quite more significant number when we imagine that each animal was assessed several times with repeated cystometry and biopsy. A total of 45 biopsies were performed in the group using the expander and 42 in the control group.

We histologically demonstrated the growth of urinary epithelium in the de-epithelialized graft in all studied samples.

The performance of cystographies and excretory urographies was also important in order to better documenting and comparing the morphology of confectioned neobladders.

We concluded that the use of the intravesical silicone modeler prevented retraction of the neobladder of de-epithelialized ileum.

Prof. Romero Glasner drew the illustrations contained in this work, and Silimed, Rio de Janeiro, supplied the vesical modelers.

\section{REFERENCES}

1. Simon J: Ectopia vesica; operation for temporary success; autopsy. Lancet. 1852; 2: 568-70.

2. Mikulicz J: Zur Operation der angeborenen. Belsanesn plate. Zentralb Chir. 1899; 26: 641-3.

3. Leong CH, Ong GB: Gastrcystoplasty in dogs. Aust N Z J Surg. 1972; 41: 272-9.

4. Nurse DE, Mundy AR: Metabolic complications of cystoplasty. Br J Urol. 1989; 63: 165-8.
5. Shoemaker WC: Reversed seromuscular grafts in urinary tract reconstruction. J Urol. 1955; 74: 453-75.

6. Filmer RB, Spencer JR: Malignancies in bladder augmentations and intestinal conduits. J Urol. 1990; 143: 671-8.

7. Martin LSJ: Uroepithelial lined ileal segment as a bladder replacement, experimental observations and brief review of literature. J Urol. 1959; 82: 633.

8. Dewan PA, Lorenz C, Stefanek W, Byard RW: Urothelial lined colocystoplasty in a sheep model. Eur Urol. 1994; 26: 240-6.

9. Buson H, Manivel JC, Dayan CM, Long R, Gonzalez R: Seromuscular colocystoplasty lined with urothelium: experimental study. Urology. 1994; 44: 743-8.

10. Lutz N, Frey P: Enterocystoplasty using modified pedicled, detubularized, de-epithelialized sigmoid patches in the mini-pig model. J Urol 1995; 154: 8938.

11. Duel BP, Gonzalez R, Barthold JS: Alternatives techniques for augmentation cystoplasty. J Urol. 1998; 159: 998-1005.

12. Lima SV, Araujo LA, Montoro M, Maciel A, Vilar FO: The use of demucosalized bowel to augment small contracted bladders. Br J Urol. 1998; 82: 436-9.

13. Jednak R, Schimke CM, Barroso JR U, Barthold JS, González R: Further experience with seromuscular colocystoplasty lined with urothelium. J Urol. 2000; 164: 2045-9.

14. Merguerian P, Chavez DR, Hakim S: Grafting of cultured uroepithelium and bladder mucosa into de-epithelialized segments of colon in rabbits. J Urol. 1994; 152: 671-4.

15. Frey P, Lutz N, Leuba AL: Augmentation cystoplasty using pedicled and de-epithelialized gastric patches in the mini-pig model. Urol. 1997; 156: 608-13.

16. Aktu T, Zdem RTÖ, Aartan C, Özer E, Olguner M, Akgür FM: Experimetally prefabricated bladder. J Urol. 2001; 165: 2055-8.

Correspondence address:

Dr. Fábio de Oliveira Vilar

Av. Flor de Santana, 189 / 502

Recife, PE, 52060-290, Brazil

E-mail:urology@salvador.net 